\title{
The Requirement for Increasingly Effective Societal Cancer Control Efforts
}

\author{
Maurie Markman ${ }^{1,2}$ \\ (C) Springer Science+Business Media, LLC, part of Springer Nature 2018
}

At a time of revolutionary changes in our understanding of the basic molecular biology of cancer, the oncology community is confronted with a most perplexing (or to be blunt, distressing) situation.

The rapidly accumulating increase in knowledge has resulted in advances in the treatment of many, if not most, cancers with documented improvements in both cancerspecific survival and quality-of-life. However, the introduction of new therapies and technologies which in many situations have begun to transform advanced and metastatic cancers into serious but more "chronic illnesses" where therapy must be delivered over an increasing number of "years" rather than only "several months or weeks" has severely strained the financial resources of individuals, families, regions, and countries.

Novel anti-neoplastic drugs now routinely cost the purchaser (individual, third party private insurer, governmental health program) more than US $\$ 10,000$ per month with the financial burden associated with multiple treatments (including combination anti-neoplastic therapy and supportive care medications, radiation, surgery) as well as physician and hospitalization expenses exceeding US $\$ 200,000$ or even US $\$ 300,000$ per year. And as noted, effective treatments may be continued for an increasingly prolonged period of time. Clearly, this scenario is financially unsustainable, either at the individual or societal level.

As a result, the successful development of useful and costeffective cancer control efforts, including both prevention and screening strategies within a given region/country and throughout the world becomes ever more relevant.

In this supplement of Current Oncology Reports, a group of well-established investigators from France (the EDIFICE group) reports their findings of surveys conducted among the public regarding awareness and valve of various cancer control strategies involving different malignancies. The readership of this journal will find the data well-presented and the analysis clear, provocative, and helpful for planning future cancer control efforts both in France and other countries.

\section{Compliance with Ethical Standards}

Conflict of Interest Maurie Markman declares that he has no conflict of interest.

Human and Animal Rights and Informed Consent This article does not contain any studies with human or animal subjects performed by any of the authors.
Maurie Markman

Maurie.Markman@ctca-hope.com

Cancer Treatment Centers of America, Philadelphia, PA, USA

2 Drexel University College of Medicine, Philadelphia, PA, USA 